\title{
Whisker stable isotope values indicate long-term foraging strategies for female New Zealand sea lions
}

\author{
B. Louise Chilvers* \\ Wildbase, School of Veterinary Science, Massey University, Private Bag 11222, Palmerston North 4442, New Zealand
}

\begin{abstract}
Determining the foraging strategies for top marine predators is fundamental to understanding their role in the marine ecosystem and essential to gain insight into how species and populations may respond to environmental variability and human impacts. The long-term foraging strategies of individuals can be studied using stable isotope analysis of whiskers, which archive keratinous tissue. Here, stable isotope analysis $\left(\delta^{13} \mathrm{C}\right.$ and $\left.\delta^{15} \mathrm{~N}\right)$ along the length of whiskers from female New Zealand (NZ) sea lions Phocarctos hookeri was used to investigate individuals' long-term foraging strategies. Previous telemetry studies showed that individual female NZ sea lions have one of 2 distinct foraging strategies that are habitual within and between years. Furthermore, past stable isotope research showed that these 2 distinct foraging strategies, i.e. benthic (foraging on the sea floor) or mesopelagic (foraging at various depths in the water column), can be identified through $\delta^{13} \mathrm{C}$ and $\delta^{15} \mathrm{~N}$ stable isotope values from blood and whiskers. In the present study, chronological serial stable isotope sampling of female NZ sea lion whiskers confirmed long-term consistency of individual foraging strategies. Thirty-one of 35 individuals showed constant benthic $(n=13)$ or mesopelagic $(n=18)$ isotopic values along the length of their whiskers. The remaining 4 individuals showed mesopelagic foraging strategies but with slight oscillations. Serial stable isotope analysis of whiskers is a powerful tool for investigating the ecological niche of top marine predators throughout their adult life. This tool can be used within the Auckland Islands' NZ sea lion population to determine the proportion of the female population that are exposed to detrimental interactions with fisheries.
\end{abstract}

KEY WORDS: Phocarctos hookeri $\cdot$ Fisheries interactions $\cdot$ Diet $\cdot$ Foraging $\cdot$ Stable isotope

\section{INTRODUCTION}

Recognising the individual variability of foraging behaviour of marine predators is important for understanding their role in the marine ecosystem and identifying how species may respond to environmental variability or human impacts. Individuals within a population can vary considerably in the way they use habitats and resources. This variation may differ across season, migratory patterns, age or sex (Cherel et al. 2009, Newsome et al. 2010, Silva et al. 2014, Kernaléguen et al. 2015a,b). Documenting individual

\footnotetext{
${ }^{*}$ Corresponding author: b.l.chilvers@massey.ac.nz
}

specialisation or niche use has implications for the population or species ecology, evolution, and conservation (Bolnick et al. 2003, Ingram et al. 2018). In marine mammals, observational studies have documented numerous examples of foraging specialisation, such as using sponges to feed in the benthos (Smolker et al. 1997), using anthropogenic food sources such as following trawlers for food or habitually being hand-fed (Chilvers \& Corkeron 2001), or fishing behaviours where cetaceans strand themselves on the beach to corral and consume fish (Sargeant et al. 2005), as have studies using remote

() The author 2019. Open Access under Creative Commons by Attribution Licence. Use, distribution and reproduction are unrestricted. Authors and original publication must be credited. 
sensing, satellite and diving behaviour data (Page et al. 2006, Staniland \& Robinson 2008, Chilvers \& Wilkinson 2009, Staniland et al. 2010).

Increasingly in the marine environment, stable isotope analysis is being used to quantify foraging strategies, at both the individual and population levels, as it is a less costly and less invasive research method than satellite tracking research (Bearhop et al. 2004, Newsome et al. 2010, Lowther \& Goldsworthy 2011, Ramos \& Gonzalez-Solis 2012, Chilvers 2017a). Stable carbon $\left(\delta^{13} C\right)$ and nitrogen $\left(\delta^{15} N\right)$ isotope ratios of marine predators define the isotopic niche along 2 dimensions, with $\delta^{13} \mathrm{C}$ and $\delta^{15} \mathrm{~N}$ values reflecting predators' foraging habitat and trophic level, respectively (Newsome et al. 2010). Analysis of different tissues reflects diet and foraging behaviour over different timescales (Crawford et al. 2008). For longer-term investigation of diet and foraging strategies of individuals, inert keratinised tissues (i.e. whiskers) 'record' the stable isotope ratio at the time of growth, but this remains unchanged once whiskers have grown (Cherel et al. 2009). Samples of whiskers taken from the proximal (base) end of the whisker represent the most recently laid-down tissue. Consequently, isotopic values and diet/foraging strategies from the last weeks to months, depending on an animal's whisker growth rate, are embedded in the tissue, and so as the whisker grows outwards, the whisker 'records' and represents the foraging strategies of an animal's life (Cherel et al. 2009, McHuron et al. 2016).

In pinnipeds, seasonal, inter-annual and decadal differences in the diets of individuals have been detected and related to fluctuations in prey availability, oceanographic conditions and migratory patterns (i.e. Hall-Aspland et al. 2005, Cherel et al. 2009, Drago et al. 2009, Hanson et al. 2009). For many pinnipeds, e.g. Otariidae (eared seals) and Phocidae (true seals), species-specific, breeding behaviour (physiological processes), individual foraging strategies and migration patterns have been described using stable isotopes (Aurioles-Gamboa et al. 2009, Cherel et al. 2009, Eder et al. 2010, Arnould et al. 2011, Lowther \& Goldsworthy 2011, Cardona et al. 2017).

The New Zealand (NZ) sea lion Phocarctos hookeri (Gray, 1844) is New Zealand's only endemic pinniped and is listed as Endangered by the IUCN (Chilvers 2015). The majority of the species (69\%) breed at the Auckland Islands $\left(50^{\circ} 30^{\prime} \mathrm{S}, 166^{\circ} \mathrm{E}\right.$; Chilvers \& Meyer 2017). NZ sea lions have had a $48 \%$ decline in pup production since 1998, driven by a declining adult population, particularly females at the Auck- land Islands (Chilvers 2012, Chilvers \& Meyer 2017). Fisheries by-catch is the only documented anthropogenic impact on NZ sea lions at the Auckland Islands (Robertson \& Chilvers 2011) and is considered the main reason for the decline of adult females (Chilvers 2012, Meyer et al. 2015, 2017).

There is extensive research on the within-season foraging behaviour of lactating female NZ sea lions (Chilvers et al. 2005, 2011, 2013, Chilvers 2008a,b, 2009, Chilvers \& Wilkinson 2009). They are known to forage over the entire Auckland Island shelf, are, however, restricted in area and duration by their need to return to dependent pups. They dive almost continuously when at sea, and their diving behaviour is at or close to their physiological limits (Gales \& Mattlin 1997, Chilvers et al. 2006, Chilvers \& Wilkinson 2009). Individuals exhibit distinct foraging strategies and can be classified as either benthic (foraging on the sea floor) or mesopelagic (foraging at various, but usually deep, depths in the water column) divers based on diving behaviour (Chilvers \& Wilkinson 2009). These distinct foraging strategies correlate to foraging in specific areas of the continental shelf around the Auckland Islands, and individuals show strong fidelity to these foraging areas within and between breeding seasons (here defined as DecemberFebruary each year; Chilvers et al. 2005, 2006, Chilvers 2008a,b, Chilvers \& Wilkinson 2009). This site fidelity occurs even when there are known differences in prey distribution and environmental conditions between years (Chilvers 2008b). These diving strategies have also been identified through differences in diet by both qualitative and quantitative fatty acid analysis (Meynier et al. 2014), and in blood and proximal-whisker stable isotope values (Chilvers 2017a).

At the Auckland Islands, there is spatial and temporal overlap between commercial fisheries and the foraging areas of female NZ sea lions, predominantly between the mesopelagic foraging individuals and the arrow squid (Nototodarus gouldi) fishery (Chilvers 2008a, Chilvers \& Wilkinson 2009). The degree of overlap between the commercial fishing activities and the foraging effort of marine mammals determines the likely rate of spatial encounters between them, and is the key component in the evaluation of the extent of competition and impacts between marine mammals and fisheries (Matthiopoulos et al. 2008). Understanding what proportion of female NZ sea lions forage mesopelagically (which has the greatest overlap and therefore highest likely interaction rate with fisheries), and whether individuals' foraging strategies are constant across their adult 
lives, will allow a better understanding of what proportion of the population, and to what extent those individuals, are exposed to the impacts of fisheries interactions.

Chilvers (2017a) previously identified that for 22 female NZ sea lions, the isotopic composition of blood serum reflected the foraging strategy being undertaken that season by the individual (shown by telemetry research) and therefore their diet. Similarly, blood serum and the proximal whisker growth have similar values, reflecting that the isotopic composition of whiskers reflects diet at the time of their growth. The present research investigates the foraging strategies in adult female NZ sea lions using stable isotope values obtained from serially sampling along the length of their whiskers. This methodology is based on the underlying principle that otariid whiskers grow continuously at a constant rate, are not shed as adults (Hirons et al. 2001, Rea et al. 2015, McHuron et al. 2016) and thus retain stable isotope records, allowing the reconstruction of an individual's diet and foraging history.

\section{MATERIALS AND METHODS}

\subsection{Sampling}

The research was undertaken at Sandy Bay, Enderby Island, Auckland Islands (Fig. 1) during the austral summers of 2009-10, 2010-11 and 2011-12. Thirty-five lactating female NZ sea lions, who had previously been flipper-tagged as pups (see Table 1 for tag ID numbers), with known age and reproductive history, were captured using a specially designed hoop net and were physically restrained by 2 handlers. They were then anaesthetised, using isoflurane delivered with oxygen to a mask via a fieldportable vaporiser (Gales \& Mattlin 1998, Chilvers et al. 2005). The flow of anaesthetic was stopped once all procedures were undertaken, and the animal was allowed to recover and return to her pup. Following restraint, each animal was observed until it was fully conscious and had returned to the group or location where it had been captured. While anaesthetised, a SPLASH tag $(10 \times 4 \times 4 \mathrm{~cm}$; Wildlife Computers), equipped with a satellite-linked platform transmitter terminal (PTT) and a time-depth recorder (TDR), that were attached to a piece of neoprene material (Gales \& Mattlin 1998, Chilvers 2017a), was glued to the female's dorsal hair on her upper back using 2-part epoxy glue (application took 8-10 min), the most caudal whisker on the left side of each animal's face

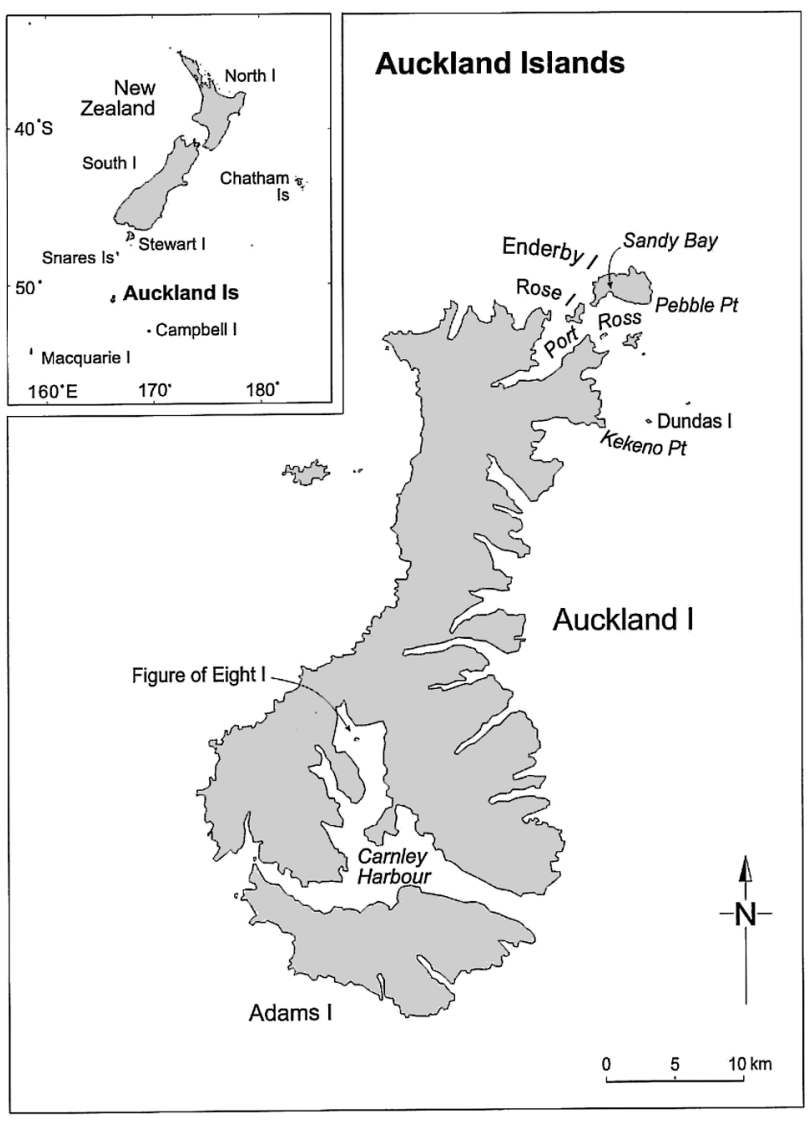

Fig. 1. New Zealand sea lion Phocarctos hookeri breeding and haul-out distribution areas, including New Zealand mainland and Campbell Islands (inset), and Auckland Islands with the site of the present research: Sandy Bay, Enderby Island

(Sadou et al. 2014) was clipped and collected, and all animals were weighed. Satellite and dive data from 22 of these individuals are published in Chilvers (2017a) and foraging strategies that were identified are presented in Table 1 here. Whiskers were cut as close to the face as possible (to remove the root would have required surgical biopsy and this was considered too invasive and not part of the permit) and stored in individual plastic bags until they were cleaned just before analysis.

\subsection{Isotopic analysis}

Stable isotope analysis was conducted by the Waikato Stable Isotope Unit, Department of Biological Sciences, University of Waikato, Hamilton, New Zealand. Whiskers were cleaned individually for 5 min with distilled water, then for 5 min with $96 \%$ ethanol, followed by a final clean and scraping with 
Table 1. Age, weight, dive profile/foraging type and stable isotope values from whiskers of 35 female New Zealand sea lions Phocarctos hookeri. Foraging type determined by time-depth recorder dive data for 22 females (see Chilvers 2017a), all others including all 'Osc meso' females determined by using stable isotope analysis of proximal whisker. Means presented \pm SE. Differences between pooled whisker samples for each foraging strategy were tested using general linear models (GLM), with Tukey's b tests used for post hoc comparisons as indicated by differing superscript letters representing significantly different values between foraging type means. Benthic $=$ benthic dive profile, Meso $=$ mesopelagic dive profile, Osc meso $=$ mesopelagic foragers that showed oscillation in their whisker chronology, $\mathrm{r}=$ correlation between $\delta^{15} \mathrm{~N}$ and $\delta^{13} \mathrm{C}$, ns = not significant

\begin{tabular}{|c|c|c|c|c|c|c|c|c|c|}
\hline Tag ID & $\begin{array}{c}\text { Age at } \\
\text { capture } \\
(y r)\end{array}$ & $\begin{array}{l}\text { Weight } \\
(\mathrm{kg})\end{array}$ & $\begin{array}{l}\text { Whisker } \\
\text { length } \\
(\mathrm{mm})\end{array}$ & $\begin{array}{l}\text { No. of } \\
5 \mathrm{~mm} \\
\text { sections }\end{array}$ & $\begin{array}{c}\text { Approx. } \\
\text { timescale of } \\
\text { each } 5 \mathrm{~mm} \\
\text { section (mo) }\end{array}$ & $\begin{array}{l}\text { Foraging } \\
\text { type }\end{array}$ & $\begin{array}{c}\text { Mean } \delta^{15} \mathrm{~N} \\
\text { for length } \\
\text { of whisker } \\
(\%)\end{array}$ & $\begin{array}{c}\text { Mean } \delta^{13} \mathrm{C} \\
\text { for length } \\
\text { of whisker } \\
(\%)\end{array}$ & $\mathrm{r}$ \\
\hline 1411 & 15 & 129 & 75 & 15 & 12 & Meso & $12.1 \pm 0.12$ & $-15.6 \pm 0.09$ & 0.905 \\
\hline B0581 & 12 & 116.5 & 125 & 16 & 9 & Meso & $13.4 \pm 0.08$ & $-15.2 \pm 0.04$ & 0.352 \\
\hline 0415 & 12 & 119 & 145 & 25 & 6 & Meso & $14.7 \pm 0.11$ & $-15.0 \pm 0.04$ & 0.461 \\
\hline 0457 & 12 & 117 & 115 & 19 & 8 & Meso & $13.3 \pm 0.05$ & $-15.2 \pm 0.04$ & 0.256 \\
\hline 0240 & 12 & 103.5 & 110 & 22 & 7 & Meso & $12.7 \pm 0.07$ & $-15.4 \pm 0.06$ & 0.476 \\
\hline В0179 & 11 & 115 & 80 & 16 & 8 & Meso & $13.7 \pm 0.07$ & $-15.2 \pm 0.03$ & 0.782 \\
\hline 0080 & 11 & 110.5 & 80 & 16 & 8 & Meso & $13.5 \pm 0.07$ & $-15.3 \pm 0.03$ & 0.219 \\
\hline 0088 & 11 & 108.5 & 90 & 18 & 7 & Meso & $13.3 \pm 0.13$ & $-15.5 \pm 0.07$ & 0.879 \\
\hline 0117 & 11 & 119.0 & 70 & 14 & 9 & Meso & $12.4 \pm 0.06$ & $-15.7 \pm 0.04$ & 0.573 \\
\hline 0375 & 11 & 116.0 & 70 & 14 & 9 & Meso & $13.4 \pm 0.15$ & $-15.3 \pm 0.05$ & 0.826 \\
\hline 0241 & 10 & 95.5 & 70 & 14 & 9 & Meso & $12.5 \pm 0.11$ & $-15.6 \pm 0.09$ & 0.718 \\
\hline 0355 & 10 & 120 & 75 & 15 & 8 & Meso & $14.3 \pm 0.09$ & $-15.1 \pm 0.04$ & 0.315 \\
\hline 3857 & 8 & 97.5 & 65 & 13 & 7 & Meso & $12.2 \pm 0.14$ & $-15.7 \pm 0.04$ & 0.758 \\
\hline 3873 & 8 & 106.5 & 105 & 21 & 5 & Meso & $13.7 \pm 0.05$ & $-15.1 \pm 0.03$ & 0.585 \\
\hline 4775 & 7 & 107.0 & 85 & 17 & 5 & Meso & $12.2 \pm 0.09$ & $-15.9 \pm 0.07$ & 0.562 \\
\hline 5703 & 7 & 115 & 65 & 13 & 6 & Meso & $13.3 \pm 0.04$ & $-15.3 \pm 0.02$ & 0.210 \\
\hline 6135 & 7 & 90 & 110 & 18 & 5 & Meso & $13.1 \pm 0.11$ & $-15.3 \pm 0.06$ & 0.948 \\
\hline 5994 & 7 & 96 & 75 & 15 & 6 & Meso & $12.3 \pm 0.04$ & $-15.4 \pm 0.04$ & 0.149 \\
\hline 0152 & 11 & 130.0 & 65 & 13 & 10 & Osc meso & $12.1 \pm 0.16$ & $-15.7 \pm 0.10$ & 0.918 \\
\hline 0334 & 11 & 130.0 & 135 & 27 & 5 & Osc meso & $12.4 \pm 0.13$ & $-15.6 \pm 0.08$ & 0.881 \\
\hline 3926 & 8 & 108.5 & 100 & 20 & 5 & Osc meso & $12.4 \pm 0.11$ & $-15.9 \pm 0.09$ & 0.769 \\
\hline 3939 & 8 & 117.5 & 100 & 20 & 5 & Osc meso & $12.3 \pm 0.14$ & $-15.9 \pm 0.09$ & 0.899 \\
\hline 0425 & 12 & 123.5 & 155 & 31 & 5 & Benthic & $11.7 \pm 0.07$ & $-16.2 \pm 0.05$ & 0.462 \\
\hline 0019 & 12 & 115 & 145 & 29 & 5 & Benthic & $11.3 \pm 0.04$ & $-16.6 \pm 0.05$ & 0.461 \\
\hline 0119 & 11 & 116.5 & 85 & 17 & 8 & Benthic & $11.0 \pm 0.11$ & $-16.4 \pm 0.06$ & 0.641 \\
\hline 3885 & 8 & 93.5 & 95 & 19 & 5 & Benthic & $11.5 \pm 0.09$ & $-16.3 \pm 0.06$ & 0.679 \\
\hline 3853 & 8 & 100.5 & 90 & 18 & 5 & Benthic & $12.0 \pm 0.06$ & $-16.2 \pm 0.04$ & 0.455 \\
\hline 3978 & 8 & 115.5 & 115 & 23 & 4 & Benthic & $11.4 \pm 0.07$ & $-16.1 \pm 0.06$ & 0.397 \\
\hline 3998 & 8 & 106.0 & 115 & 23 & 4 & Benthic & $11.7 \pm 0.08$ & $-16.1 \pm 0.05$ & 0.641 \\
\hline 4063 & 8 & 110.5 & 95 & 19 & 5 & Benthic & $11.0 \pm 0.07$ & $-16.6 \pm 0.06$ & 0.468 \\
\hline 4726 & 8 & 121.5 & 120 & 20 & 5 & Benthic & $11.4 \pm 0.09$ & $-16.4 \pm 0.08$ & 0.805 \\
\hline 5140 & 8 & 115.5 & 115 & 19 & 5 & Benthic & $11.9 \pm 0.09$ & $-16.1 \pm 0.09$ & 0.765 \\
\hline 4840 & 7 & 118.5 & 70 & 14 & 6 & Benthic & $11.6 \pm 0.12$ & $-15.9 \pm 0.06$ & 0.725 \\
\hline 5770 & 7 & 94 & 60 & 12 & 7 & Benthic & $11.6 \pm 0.06$ & $-16.2 \pm 0.07$ & 0.488 \\
\hline 6021 & 7 & 101.5 & 135 & 27 & 3 & Benthic & $11.9 \pm 0.05$ & $-16.0 \pm 0.06$ & 0.576 \\
\hline Meso mean & $10.1 \pm 0.3$ & $110.1 \pm 2.4$ & $89.5 \pm 5.5$ & $16.7 \pm 0.8$ & $7.2 \pm 0.43^{\mathrm{b}}$ & & $13.1 \pm 0.18^{\mathrm{a}}$ & $-15.3 \pm 0.06^{\mathrm{a}}$ & $0.549 \pm 0.064^{b}$ \\
\hline Osc meso mean & $9.5 \pm 0.8$ & $121.5 \pm 5.2$ & $100 \pm 14.3$ & $20 \pm 2.8$ & $6.3 \pm 1.3^{\mathrm{a}, \mathrm{b}}$ & & $12.9 \pm 0.08^{\mathrm{b}}$ & $-15.8 \pm 0.08^{\mathrm{b}}$ & $0.867 \pm 0.033^{\mathrm{a}}$ \\
\hline Benthic mean & $8.6 \pm 0.50$ & $110.2 \pm 2.7$ & $107 \pm 7.8$ & $21 \pm 1.5$ & $5.2 \pm 0.35^{\mathrm{a}}$ & & $11.5 \pm 0.08^{c}$ & $-16.2 \pm 0.06^{\mathrm{c}}$ & $0.582 \pm 0.037^{\mathrm{b}}$ \\
\hline Significance & ns & $\mathrm{ns}$ & ns & ns & $\begin{array}{c}F=6.7 \\
\mathrm{p}=0.004\end{array}$ & & $\begin{array}{c}F=28.2 \\
\mathrm{p}<0.0001\end{array}$ & $\begin{array}{c}F=54.9 \\
\mathrm{p}<0.0001\end{array}$ & $\begin{array}{l}F=3.6 \\
\mathrm{p}=0.04\end{array}$ \\
\hline
\end{tabular}

distilled water for an additional 5 min (Cherel et al. 2009). Each whisker was checked under a stereomicroscope for any remaining tissue or dirt; contaminants were removed using a scalpel blade. All samples were then rinsed with distilled water and left to air-dry overnight. Whiskers were measured, and cut into $5 \mathrm{~mm}$ long consecutive sections starting from the proximal end. Sections $(n=219)$ were weighed with a micro-balance, packed in tin foil capsules, and $\delta^{13} \mathrm{C}$ and $\delta^{15} \mathrm{~N}$ were determined by a Dumas elemental analyser (Europa Scientific ANCA-SL) interfaced to an isotope-ratio mass spectrometer (Europa Scientific 20-20 Stable Isotope Analyser). Results are presented in the conventional $\delta$ notation calculated as the rela- 
tive variation of stable isotope ratios expressed as per mille (\%) relative to a laboratory standard/reference for sucrose and urea (the urea had been calibrated relative to atmospheric nitrogen) for $\delta^{13} \mathrm{C}$ and $\delta^{15} \mathrm{~N}$, respectively. Quality control samples were run before and after every 12 samples. Precision for $\delta^{13} \mathrm{C}$ and $\delta^{15} \mathrm{~N}$ measurements was $0.1 \%$ and $0.2 \%$ respectively.

\subsection{Statistics}

Telemetry data from the females were used to validate foraging strategy as indicated by whisker stable isotope values (see Chilvers 2017a for telemetry results). Using SPSS (version 24 for Windows), differences between pooled whisker samples for each individual's foraging strategy were tested using general linear models (GLM), with Tukey's b tests used for post hoc comparisons. Pearson's correlation (r) was undertaken to assess the correlation between $\delta^{13} \mathrm{C}$ and $\delta^{15} \mathrm{~N}$ values along each individual's whisker, and between whisker length and age or weight of individuals. Unless otherwise stated, data are presented as mean $( \pm 1 \mathrm{SE})$ and results are considered significant at $\mathrm{p}<0.05$.

\section{RESULTS}

The individual mean stable isotope values from the sequentially sampled whiskers of 35 female NZ sea lions, ranging from 7 to $15 \mathrm{yr}$ of age, are shown in Table 1, along with the Pearson's correlation coefficient between the $\delta^{13} \mathrm{C}$ and $\delta^{15} \mathrm{~N}$ values along each individual's whisker. Assuming female NZ sea lion whiskers grow continuously, at a constant rate and are not shed as adults, as seen in other otariids
(Hirons et al. 2001, Rea et al. 2015, McHuron et al. 2016), each $5 \mathrm{~mm}$ whisker section represented between 3 mo and 1 yr of each animal's life, based on dividing the female's known age by her whisker length (mean: 6 mo, Table 1). The length of whiskers ranged from 60 to $145 \mathrm{~mm}$ and the number of whisker sections analysed for each individual varied accordingly from 12 to 31 (Table 1). There were no significant correlations between whisker length and either age or weight of the individual (whisker and age: $r=0.176, p=0.3$; whisker and weight: $r=0.204$, $p=0.25$ ). Based on whisker length and known age of females, the mean whisker growth rate for adult female NZ sea lions is $0.03 \mathrm{~mm} \mathrm{~d}^{-1}$, with a range from 0.01 to $0.05 \mathrm{~mm} \mathrm{~d}^{-1}$ (although these estimates would be minimum estimates, as this would not take into consideration any wear at the whisker tip).

Overall, there were significant differences in mean $\delta^{13} \mathrm{C}$ and $\delta^{15} \mathrm{~N}$ values (Table 1 ) between females with benthic and mesopelagic foraging strategies as identified from telemetry (Chilvers 2017a), with the lowest $\delta^{13} \mathrm{C}$ values associated with the lowest $\delta^{15} \mathrm{~N}$ values, and the lowest mean $\delta^{13} \mathrm{C}$ and $\delta^{15} \mathrm{~N}$ values consistently coming from the whiskers of benthic foraging females. Fig. 2 shows the mean $\delta^{13} \mathrm{C}$ and $\delta^{15} \mathrm{~N}$ values for each $5 \mathrm{~mm}$ whisker section for mesopelagic ( $\mathrm{n}=$ $18)$ or benthic $(n=13)$ foraging adult females (sectioning starts from the proximal end of the whisker), clearly showing the differences seen in isotopic values for each foraging strategy.

Based on knowledge from the isotope and telemetry study (Chilvers 2017a), of the 35 females, 13 showed clear constant benthic foraging strategy stable isotope values across the entire length of their whisker (examples of individuals given in Fig. 3a), 18 showed a clear constant mesopelagic foraging strategy stable isotope values (examples given in Fig. 3b) and an additional 4

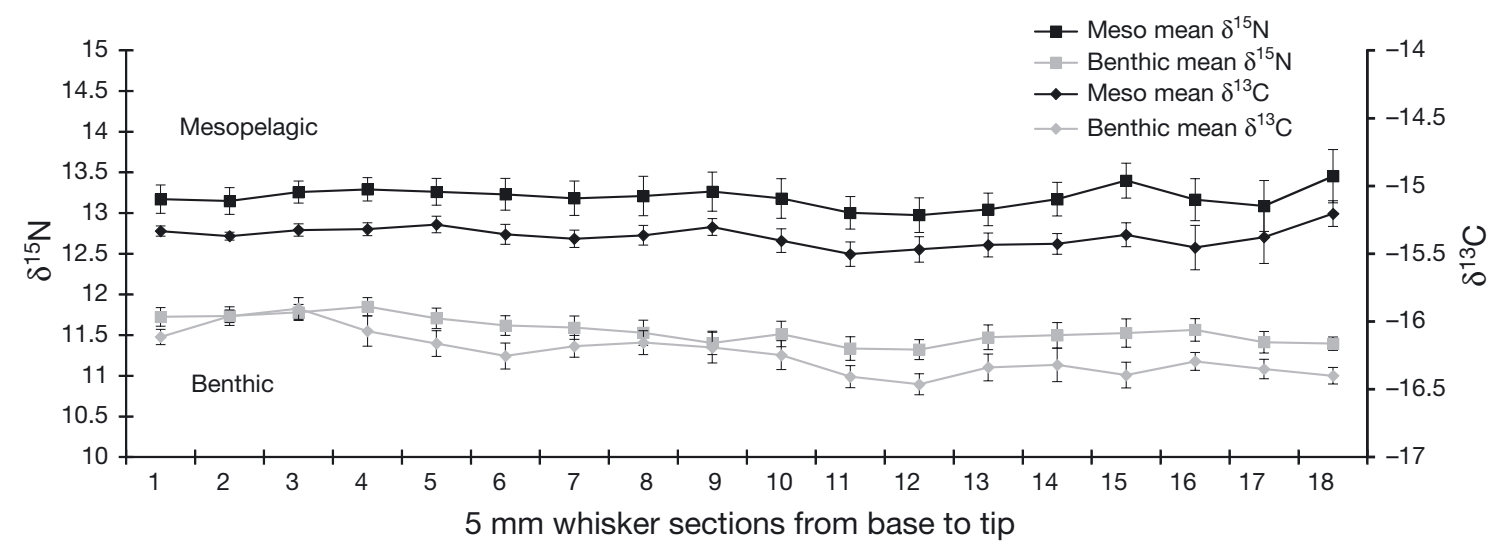

Fig. 2. Mean $\delta^{13} \mathrm{C}$ and $\delta^{15} \mathrm{~N}$ values (error bars $\left.=\mathrm{SE}\right)$ for each whisker section from mesopelagic $(\mathrm{n}=18)$ and benthic $(\mathrm{n}=13)$ foraging adult female New Zealand sea lions Phocarctos hookeri. Sectioning starts from the proximal (base) end of the whisker 


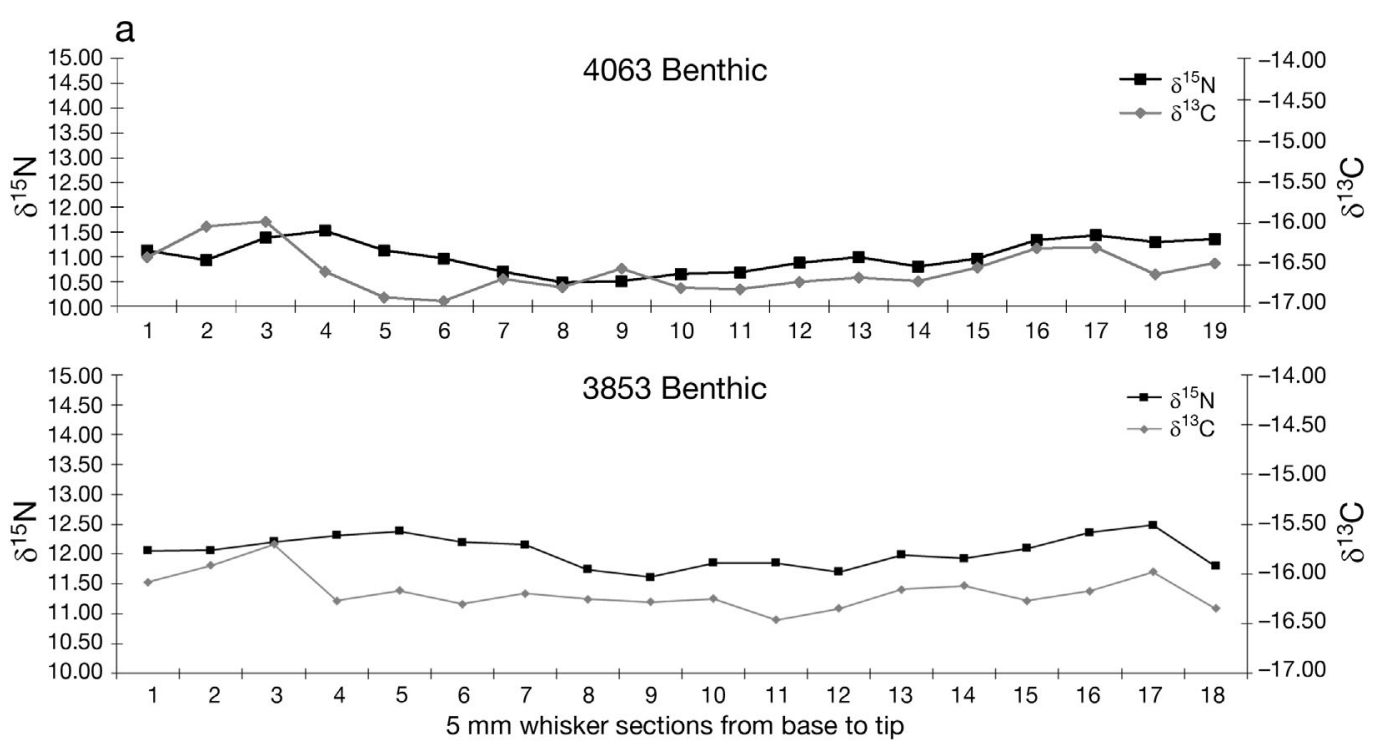

b
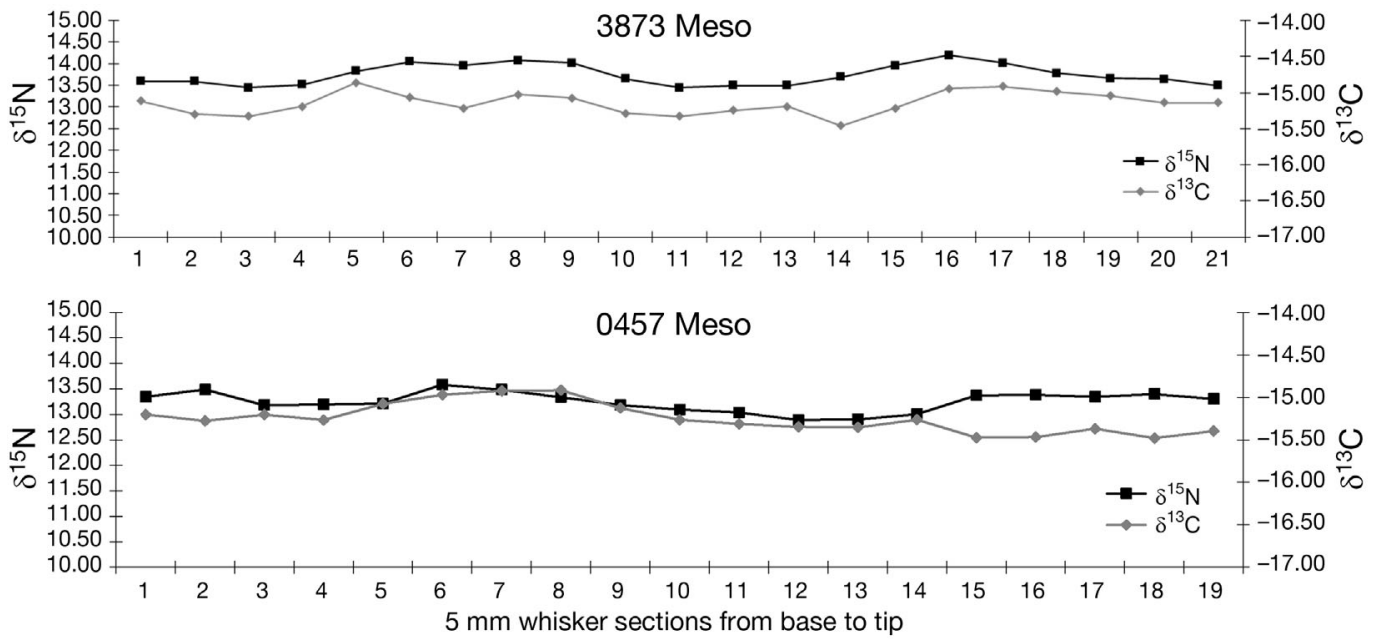

Fig. 3. $\delta^{13} \mathrm{C}$ and $\delta^{15} \mathrm{~N}$ values along the length of a whisker from (a) 2 benthic (tag IDs 4063 and 3853) and (b) 2 mesopelagic (tag IDs 3873 and 0457) foraging adult female New Zealand sea lions Phocarctos hookeri. Note different $X$-axis scales

mesopelagic females showed slight isotopic value oscillations along the length of their whiskers (Table 1, Fig. 4). Pearson's correlation between the $\delta^{13} \mathrm{C}$ and $\delta^{15} \mathrm{~N}$ values along each individual's whisker varied considerably from barely correlated to highly correlated (range of r: 0.149 to 0.948). Between the 3 foraging strategies, the oscillating mesopelagic foragers had significantly higher correlation between their $\delta^{13} \mathrm{C}$ and $\delta^{15} \mathrm{~N}$ values along their whiskers than either benthic or mesopelagic foragers. The mesopelagic foragers showed the greatest variability in correlations, with that foraging group having both the least and most correlated individuals (Table 1).

Across all individuals, whisker isotopic values were not spread over a wide range, with total $\delta^{15} \mathrm{~N}$ and $\delta^{13} \mathrm{C}$ values varying from 11 to $14.7 \%$ o (a $3.7 \%$ o differ- ence) and -16.6 to $-15 \%$ ( $1.6 \%$ difference) respectively. There was a greater range between mesopelagic foragers $(2.6 \%$ and $1.6 \%$ ) than benthic foragers ( $1 \%$ and $0.7 \%$ ), taking into consideration that the mesopelagic foragers included the 4 individuals that showed oscillation in their whisker chronology (Table 1, Fig. 4). The maximum variation in an individual's $\delta^{15} \mathrm{~N}$ and $\delta^{13} \mathrm{C}$ values from whiskers, across their whisker length, was a maximum of $2 \%$ and $1.5 \%$ respectively (individual with tag ID 0334, Fig. 4). There were statistically significant differences in mean $\delta^{15} \mathrm{~N}$ and $\delta^{13} \mathrm{C}$ values between females with benthic, mesopelagic and oscillating mesopelagic foraging strategies. Tukey's b post hoc tests showed all 3 strategies to be significantly different from each other (mean $\delta^{15} \mathrm{~N}$ values: benthic: $11.5 \%$, 

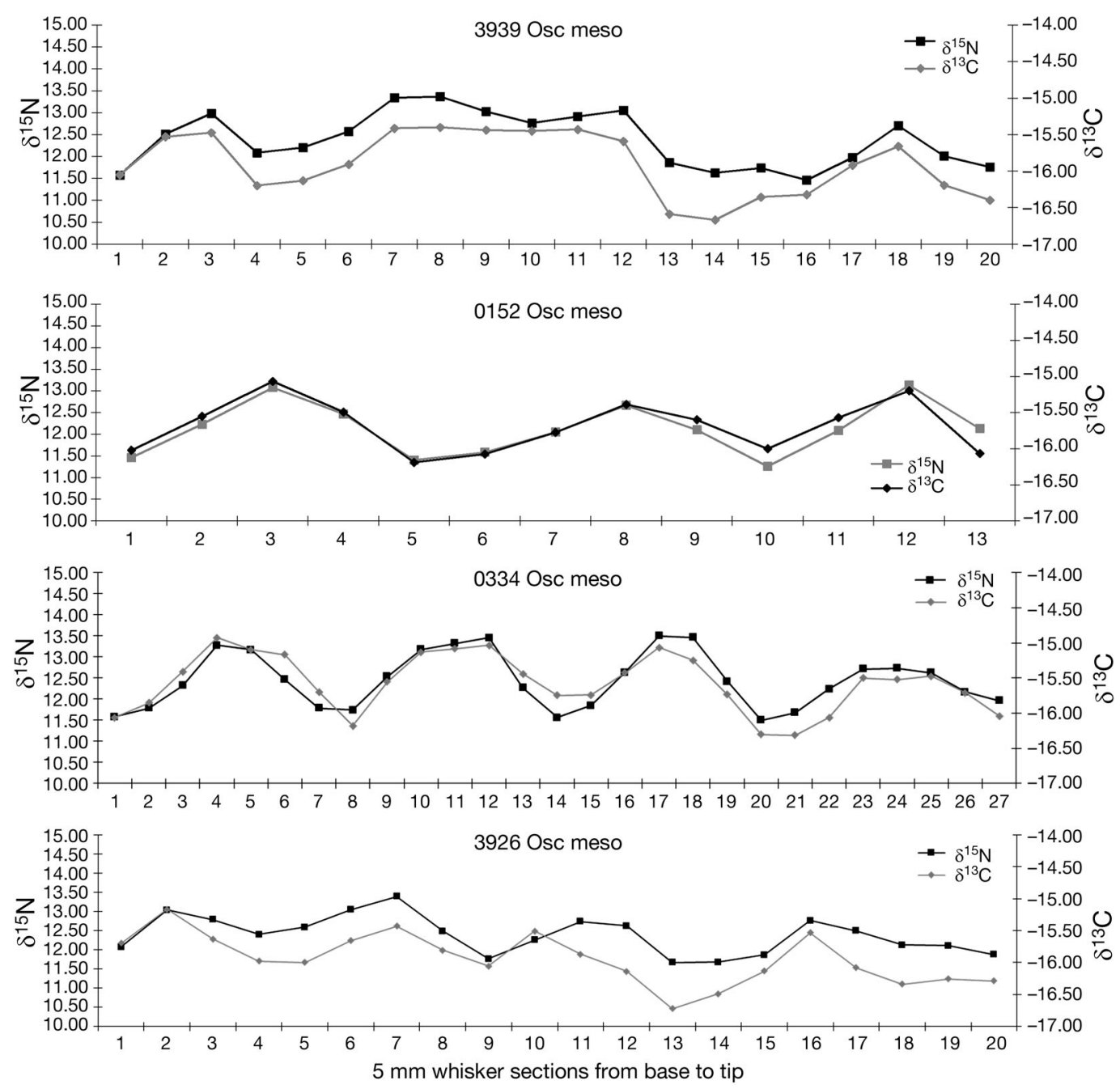

Fig. 4. $\delta^{13} \mathrm{C}$ and $\delta^{15} \mathrm{~N}$ values along the length of a whisker from the 4 oscillating mesopelagic ('Osc meso') (tag IDs 3939, 0152, 0334 and 3926) foraging adult female New Zealand sea lions Phocarctos hookeri. Note different $x$-axis scales

mesopelagic: $13.1 \%$, oscillating mesopelagic: $12.9 \%$, $F=28.2, \mathrm{p}<0.0001 ; \delta^{13} \mathrm{C}$ : benthic: $-16.2 \%$, mesopelagic: $-15.3 \%$, oscillating mesopelagic: $-15.8 \%$, $F=54.9, \mathrm{p}<0.0001$; Table 1). Benthic or mesopelagic foraging individuals as identified from dive and stable isotope data can be clearly identified from graphing individuals' mean whisker stable isotope values; however, mesopelagic and oscillating mesopelagic foraging individuals cannot (Fig. 5).

For the 4 oscillating mesopelagic foragers, whisker oscillation lengths were similar for 3 of the 4 individuals, at approximately $25 \mathrm{~mm}$ oscillations. The individual with tag ID 0334 showed a different oscillation length, of approximately $35 \mathrm{~mm}$ oscillations (Fig. 4). ID 0152 's graph only indicates 3 oscillations across her whisker length, while the other 3 individuals indicate 4 (Fig. 4).

\section{DISCUSSION}

\subsection{Chronological stable isotope sampling of whiskers}

Previous research using stable isotope values of blood serum from female NZ sea lions showed clear inter-individual variation in isotopic values reflecting their foraging behaviour collected using telemetry research and could be used to identify individuals as either mesopelagic or benthic foragers (Chilvers 2017a). Furthermore, that research identified that there were no statistically significant differences between blood serum and proximal whisker isotopic values for individuals, indicating that the clipped proximal whisker isotopic value reflects the diet and foraging strategy of the individual at the time of 


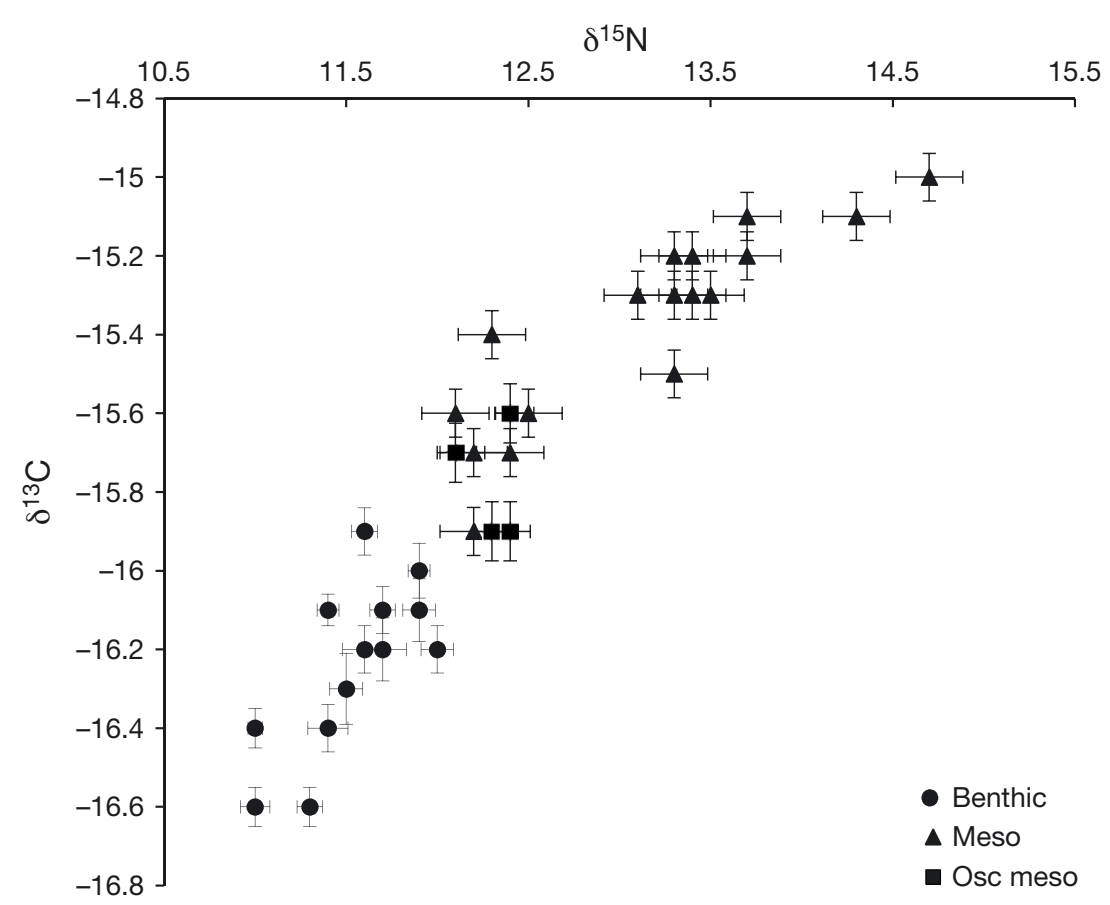

Fig. 5. Female New Zealand sea lions Phocarctos hookeri mean $\delta^{13} \mathrm{C}$ and $\delta^{15} \mathrm{~N}$ values (error bars $=\mathrm{SE}$ ) for the entire whisker length, for mesopelagic, oscillating mesopelagic ('Osc meso') and benthic foragers. Oscillating mesopelagic individuals are the 4 females with a predominantly mesopelagic foraging strategy but with variability in the $\delta^{13} \mathrm{C}$ and $\delta^{15} \mathrm{~N}$ values across the length of their whisker (see Fig. 4)

growth. As keratin composition of whiskers does not change once formed, using chronological stable isotope values from female NZ sea lions' whiskers in the present study confirms that individual female NZ sea lions have consistent long-term within- and betweenyear fidelity in diet and foraging strategy. This consistency is despite known changes in their environment, age and reproductive status (Chilvers 2009). Individuals can be clearly identified as either benthic or mesopelagic foragers from their isotopic values (Figs. 2 \& 5).

The predominant difference in whisker stable isotope values from the 2 female NZ sea lion foraging strategies is that mesopelagic foragers have significantly higher $\delta^{15} \mathrm{~N}$ and $\delta^{13} \mathrm{C}$ values than benthic foragers (Table 1 in the present study; Chilvers 2017a), which can also be seen along the entire length of their whiskers (Figs. 2 \& 3). This finding matches fatty-acid diet analysis for NZ sea lions which shows that mesopelagic foragers consume prey or a higher proportion of prey from a higher trophic level (i.e. finfish compared with cephalopods) than the benthic foragers (Meynier et al. 2014).

Thirty-one of the 35 individuals investigated in the present research show very little range in their indi- vidual $\delta^{15} \mathrm{~N}$ and $\delta^{13} \mathrm{C}$ values across their whisker length, with no sign of decline or increase in either value with age or known differences in reproductive status. Even the individuals that do show slight oscillations in signature values are within a restricted range, with the greatest individual variation in $\delta^{15} \mathrm{~N}$ and $\delta^{13} \mathrm{C}$ values being $2 \%$ and $1.5 \%$ respectively, with none of the values outside the overall ranges of mesopelagic foragers. These small ranges of stable isotope values indicate and support the hypothesis that female NZ sea lions have a restricted diet (Meynier et al. 2014) and lack any form of migration or movement away from the Auckland Islands area (Chilvers \& Wilkinson 2008; see further discussion in Section 4.3 below).

\subsection{Stable isotope values and whisker growth}

Stable isotope analysis of whiskers allows the question of dietary specialisations, inter-annual behaviour and long-term foraging site fidelity of pinnipeds to be investigated. However, to utilise this method, data describing the growth rate and duration of tissue deposition of species are required to best identify the timespan of representation within each whisker and to link the encoded isotope values to specific ecological and life history events (Cardona et al. 2017). A limitation of this research is that it can only be assumed that female NZ sea lion whiskers grow continuously, at a constant rate, and are not shed as adults, as seen in other otariids (Hirons et al. 2001, McHuron et al. 2016). There are no NZ sea lion species-specific data to confirm otherwise and this is an area of research for NZ sea lions. It is likely this has not been undertaken because it could only be undertaken on wild individuals, as there has never been a NZ sea lion kept in captivity, and until the last decade, the species has been predominantly restricted to the remote NZ subantarctics, which restricts access to animals within and across years.

The assumption that female NZ sea lions' whiskers grow at a continuous linear rate and are not shed as adults is a fair assumption, given that all other otariids that have been investigated show this trait 
(Hirons et al. 2001, Kernaléguen et al. 2012, 2015b, Rea et al. 2015, McHuron et al. 2016, Cardona et al. 2017). It is the rate of whisker growth and differences between individuals that is a specific unknown for this research, and that shows great variability within and across other otariid species (see Table 1 in McHuron et al. 2016 for a summary). Minimum mean whisker growth rate for female NZ sea lions from the present research was estimated at $0.03 \mathrm{~mm} \mathrm{~d}^{-1}$, with a range from 0.01 to $0.05 \mathrm{~mm} \mathrm{~d}^{-1}$, a small range showing little variation across 35 individuals compared to other sea lion species (McHuron et al. 2016). This represents the lower end of other otariid species' growth rate ranges (Hirons et al. 2001, Cherel et al. 2009, Kernaléguen et al. 2012, 2015a,b, Rea et al. 2015, Cardona et al. 2017), except for California sea lions Zalophus californianus, the species which matches NZ sea lions the closest in body size and growth rate of all the otariids that have had whisker growth measured.

\subsection{Stable isotope values and foraging strategy}

There were 4 mesopelagic foraging female NZ sea lions that showed oscillations in isotope values along their whiskers' length. For pinnipeds, isotopic values in whiskers are known to vary as a function of diet and/or physiological processes such as reproductive status (Cardona et al. 2017). In the Southern Ocean, both $\delta^{15} \mathrm{~N}$ and $\delta^{13} \mathrm{C}$ values vary with latitude and along an inshore/offshore gradient (Cherel \& Hobson 2007). Usually, consistent isotopic oscillations along whisker lengths are seen in individuals that make annual movements or migrations between subtropical, subantarctic and Antarctic feeding zones, such as male Antarctic fur seals Arctocephalus gazella (Cherel et al. 2009). However, the oscillations of male Antarctic fur seals are associated with large changes in $\delta^{15} \mathrm{~N}$ and $\delta^{13} \mathrm{C}$ values (up to $5 \%$ and $6 \%$ respectively; Cherel et al. 2009) as both diet and latitudes of the individuals change. The changes seen in the oscillations of female NZ sea lions are much smaller and within the overall range of any of the consistently mesopelagic foraging females. This indicates that these changes are more likely to be from changes in the proportions of different prey species in the diet rather than movements away from the area (Meynier et al. 2014), or may be from changes in $\delta^{15} \mathrm{~N}$ and $\delta^{13} \mathrm{C}$ levels due to reproductive status, as has been shown in a female South American sea lion Otaria byronia (Cardona et al. 2017). From sighting records of the 4 mesopelagic females that show oscil- lations in whisker isotope values in the present study, all were seen annually in the breeding harem at Enderby Island from the age of $3 \mathrm{yr}$ until the year of their captures and whisker removal (and beyond), except for $0152 \mathrm{who}$, in 2007 at the age of $7 \mathrm{yr}$, was not re-sighted that single year, but was seen again the following years. All 4 animals pupped at least twice before and in the year of their capture (unpubl. data, NZ Department of Conservation NZ sea lion database, https://sealions.dragonfly.co.nz/demographics/); however, none of the gestations, births or lactation periods appear to match what would be expected if these reproductive stressors physiologically impacted the stable isotope values for these individuals (Cardona et al. 2017, our Fig. 4). For example, female 0152, who showed 3 long oscillations, pupped when she was $6,9,10$ and $11 \mathrm{yr}$ of age (the year her whisker was sampled, Fig. 4), and none of these reproductive events appear to affect stable isotope values along her whisker. Additionally, if there was significant influence on stable isotope values from physiological processes like gestation and lactation, this should be seen in all the females, as all of the females in the present study had previously pupped (unpubl. data, NZ Department of Conservation NZ sea lion database, as above). In addition, Cardona et al. (2017) found that these physiological changes impact $\delta^{15} \mathrm{~N}$ and $\delta^{13} \mathrm{C}$ differently, with $\delta^{13} \mathrm{C}$ values increasing during pregnancy, and $\delta^{15} \mathrm{~N}$ values decreasing during lactation, meaning these individuals had low correlation values between $\delta^{15} \mathrm{~N}$ and $\delta^{13} \mathrm{C}$ along the whiskers. This was not seen for the oscillating mesopelagic foraging female NZ sea lions, which all had high correlation between $\delta^{15} \mathrm{~N}$ and $\delta^{13} \mathrm{C}$ along the length of their whiskers (Table 1). Additionally, assuming the actual timescale for each $5 \mathrm{~mm}$ whisker section for each individual is close to the estimated timescale (months shown in Table 1), and given the indicated oscillation lengths in the graphs (Fig. 4), it appears that oscillations for the individuals tagged as ID 3926 and ID 3939 occur once every 2 yr, every 3 yr for ID 0334 and every 4 yr for ID 0152. This indicates that these are not annual migrations, and supports that they are unlikely to be physiological processes, given the reproductive histories of the females, but are more likely to reflect changes in the prey consumed.

\subsection{Stable isotope values and age}

There was no drop in $\delta^{15} \mathrm{~N}$ isotope values observed in whiskers from these female NZ sea lions; such a 
drop occurs during weaning, when a pup stops suckling from the high trophic-level food source of its mother's milk, and begins to forage on its own on lower trophic-level food sources (Kernaléguen et al. 2012). A significant drop in $\delta^{15} \mathrm{~N}$ isotope values has previously been recorded in bones and teeth of marine mammals (Newsome et al. 2010) and was seen for the first time in 2 (out of 10) female subantarctic fur seals A. tropicalis in the Crozet area (Kernaléguen et al. 2012). A drop in $\delta^{15} \mathrm{~N}$ isotope values reflective of weaning would occur at the tip of the whisker furthest from the face. With none of the female NZ sea lions showing a drop in $\delta^{15} \mathrm{~N}$ isotope values, this suggests the tip of all the whiskers had broken or worn off or that NZ sea lion pups or juveniles lose their whiskers. Whisker growth rate and shedding research is needed in NZ sea lions to best identify the timespans the stable isotope values presented here represent.

Except for the significant drop in $\delta^{15} \mathrm{~N}$ values at weaning, there have been few studies that have documented age-related differences in the trophic niches of adult pinnipeds. Drago et al. (2009) observed no significant differences in $\delta^{15} \mathrm{~N}$ values with age in South American sea lions; however, they observed an increase in $\delta^{13} \mathrm{C}$ suggestive of a shift to more benthic prey species in older animals. Adult female Australian fur seals A. pusillus showed a decrease in $\delta^{15} \mathrm{~N}$ with age, indicating they were consuming increasing amounts of lower trophic-level prey with age (Kernaléguen et al. 2015b). In the present study, there were no changes in overall isotope values for female NZ sea lions up to the age of $15 \mathrm{yr}$. Again, this shows the consistency and fidelity of their foraging strategies year in and year out, with age, reproductive status, and likely also with naturally occurring changes in environmental conditions, such as the effects of the Southern Oscillation (Chilvers 2009).

\subsection{NZ sea lions and fisheries interactions}

The long-term individual foraging strategy and diet specialisation of this population confirm that this population is likely to be highly susceptible to, and less able to respond to, environmental changes or anthropogenic impacts such as fisheries resource competition (Costa 1993, Bolnick et al. 2003, Chilvers et al. 2006).

Being able to collect and analyse stable isotope values, and therefore identify adult foraging strategies, from whiskers of female NZ sea lion is a far faster, less invasive and more cost-effective method than undertaking satellite-based foraging studies. This is an important finding for female NZ sea lions at the Auckland Islands because fisheries by-catch is the largest documented anthropogenic impact on the population there (Robertson \& Chilvers 2011, Meyer et al. 2015, 2017), and fisheries interactions and therefore by-catch are more likely to occur on mesopelagic foraging females than benthic foraging females (Chilvers \& Wilkinson 2009, Robertson \& Chilvers 2011). Understanding the proportion of females having mesopelagic foraging strategies and unchanging foraging strategies across their adult life (or at least for the years of their whisker length) gives a better understanding of what proportion of the population is exposed to the fisheries interaction risk of by-catch and resource competition.

\section{CONCLUSIONS}

There are numerous next steps to be taken in stable isotope research for NZ sea lions. Research should include studies investigating whisker growth and retention rates, and stable isotope values and foraging strategies in age and sex classes that are not as easy to undertake foraging research on (i.e. juveniles and adult males). Similar to other otariids (Drago et al. 2010, Lowther \& Goldsworthy 2011), it would also be useful to identify links between female foraging strategies and pup whisker stable isotope values. This would be an even easier, more cost-effective way of identifying foraging strategies for lactating females and therefore fisheries interactions, as it would mean only pups would need to be handled and have their whiskers clipped.

This research confirms that female NZ sea lions at the Auckland Islands are showing long-term individual fidelity to diet, foraging location and strategy. Therefore, this population is likely to be highly susceptible to environmental change and anthropogenic impacts, as they cannot or do not have the ability to alter foraging strategies when conditions change (Costa 1993, Gales \& Mattlin 1997, Bolnick et al. 2003, Chilvers et al. 2006). Additionally, of the 35 females studied here, $63 \%$ showed mesopelagic foraging specialisation, putting their foraging area in direct overlap with local fisheries (Chilvers \& Wilkinson 2009, Robertson \& Chilvers 2011). The continued fisheries interactions, with the probable indirect competition effects and known mortality in the local fisheries are a serious concern for this endangered, declining species. This applies in particular to the Auckland Islands 
population, which represents $69 \%$ of the species, with potentially more than half of the breeding females in the population being directly exposed to fisheries interactions (Chilvers \& Wilkinson 2009, the present study). The direct fisheries interactions continue, with 3 individuals known killed in 2017 and 15 estimated deaths, and 2 individuals known killed in 2018 and 18 estimated deaths (unpubl. weekly report, 6 June 2018, Team Manager Deepwater Fisheries, NZ Fisheries). This population already shows low and late reproductive output for females, extremely low milk-fat content and low pup growth rates in comparison to other otariid species and even compared to this species outside of the NZ subantarctics (Chilvers et al. 2007, 2010, Augé et al. 2011, Chilvers 2017b). All indicators show that this population of NZ sea lions cannot sustain this level of fisheries interactions, and meaningful and measurable procedures to mitigate impacts of fisheries need to be undertaken (Chilvers 2008a, Robertson \& Chilvers 2011, Meyer et al. 2015, 2017).

Acknowledgements. I thank Anjana Rajendram from the Waikato Stable Isotope Unit, Department of Biological Sciences, University of Waikato for the stable isotope analysis. Data presented in this paper were collected with funding from the NZ Department of Conservation (DOC), in parallel with fieldwork undertaken for the DOC Marine Conservation Services Programme (www.doc.govt.nz/mcs) project. Approval for all work was obtained from the DOC Animal Ethics Committee (Approvals AEC 200, 2 Nov 2009). Thanks to Bridey White and 2 anonymous reviewers, all of whom provided helpful, critical reviews of the manuscript, and last but by no means least, an enormous thank you to all the people who have worked in the field collecting these data.

\section{LITERATURE CITED}

Arnould JPY, Cherel Y, Gibbens J, White JG, Littnan CL (2011) Stable isotopes reveal inter-annual and inter-individual variation in the diet of female Australian fur seals. Mar Ecol Prog Ser 422:291-302

Augé AA, Chilvers BL, Moore AB, Davis LS (2011) Foraging behaviour indicates marginal marine habitat for New Zealand sea lions: remnant versus recolonising populations. Mar Ecol Prog Ser 432:247-256

Aurioles-Gamboa D, Newsome SD, Salazar Pico S, Koch PL (2009) Stable isotope differences between sea lions (Zalophus) from the Gulf of California and Galápagos Islands. J Mammal 90:1410-1420

Bearhop S, Adams CE, Waldron S, Fuller RA, MacLeod H (2004) Determining trophic niche width: a novel approach using stable isotope analysis. J Anim Ecol 73: 1007-1012

Bolnick DI, Svanback R, Fordyce JA, Yang LH, Davis JM, Hulsey CD, Forister ML (2003) The ecology of individuals: incidence and implications of individual specialization. Am Nat 161:1-28

Cardona L, Vales D, Aguilar A, Crespo E, Zenteno L (2017)
Temporal variability in stable isotope ratios of $\mathrm{C}$ and $\mathrm{N}$ in the vibrissa of captive and wild adult South American sea lions Otaria byronia: more than just diet shifts. Mar Mamm Sci 33:975-990

* Cherel Y, Hobson KA (2007) Geographical variation in carbon stable isotope signatures of marine predators: a tool to investigate their foraging areas in the Southern Ocean. Mar Ecol Prog Ser 329:281-287

* Cherel Y, Kernaleguen L, Richard P, Guinet C (2009) Whisker isotopic signature depicts migration patterns and multiyear intra- and inter-individual foraging strategies in fur seals. Biol Lett 5:830-832

* Chilvers BL (2008a) New Zealand sea lions Phocarctos hookeri and squid trawl fisheries: bycatch problems and management options. Endang Species Res 5:193-204

Chilvers BL (2008b) Foraging behaviour site fidelity of lactating New Zealand sea lions, Phocarctos hookeri. J Zool 276:28-36

Chilvers BL (2009) Foraging locations of a decreasing colony of New Zealand sea lions (Phocarctos hookeri). N Z J Ecol 33:106-113

* Chilvers BL (2012) Population viability analysis of New Zealand sea lions, Auckland Islands, New Zealand's subAntarctics: assessing relative impacts and uncertainty. Polar Biol 35:1607-1615

Chilvers BL (2015) Phocarctos hookeri. In: IUCN Red List of Threatened Species, version 2015.2. www.iucnredlist. org (accessed on 3 July 2018)

Chilvers BL (2017a) Stable isotope signatures of whisker and blood serum confirm foraging strategies for female New Zealand sea lions derived from telemetry. Can J Zool 95: 955-963

Chilvers BL (2017b) Preliminary assessment of the foraging behaviour and population dynamics of a cryptic population of the endangered New Zealand sea lion. N Z J Ecol 42:48-57

Chilvers BL, Corkeron PJ (2001) Trawlers and bottlenose dolphins' social structure. Proc R Soc B 268:1901-1905

*Chilvers BL, Meyer S (2017) Conservation needs for the endangered New Zealand sea lion. Aquat Conserv 27: 846-855

Chilvers BL, Wilkinson IS (2008) Philopatry and site fidelity of New Zealand sea lions (Phocarctos hookeri). Wildl Res 35:463-470

Chilvers BL, Wilkinson IS (2009) Diverse foraging strategies in lactating New Zealand sea lions. Mar Ecol Prog Ser 378:299-308

Chilvers BL, Wilkinson IS, Duignan PJ, Gemmell NJ (2005) Summer foraging areas for lactating New Zealand sea lions Phocarctos hookeri. Mar Ecol Prog Ser 304:235-247

Chilvers BL, Wilkinson IS, Duignan PJ, Gemmell N (2006) Diving to extremes: Are New Zealand sea lions (Phocarctos hookeri) pushing their limits in a marginal habitat? J Zool 269:233-241

Chilvers BL, Robertson BC, Wilkinson IS, Duignan PJ (2007) Growth and survival of New Zealand sea lions, Phocarctos hookeri: birth to 3 months. Polar Biol 30:459-469

Chilvers BL, Wilkinson IS, MacKenzie DI (2010) Predicting life-history traits for female New Zealand sea lions, Phocarctos hookeri: integrating short-term mark-recapture data and population modelling. J Agric Biol Environ Stat 15:259-278

* Chilvers BL, Amey JM, Huckstadt LA, Costa DP (2011) Investigating foraging utilization distribution of female New Zealand sea lions. Polar Biol 34:565-574 
Chilvers BL, Childerhouse SJ, Gales NJ (2013) Winter foraging behaviour of lactating New Zealand sea lions Phocarctos hookeri. N Z J Mar Freshw Res 47:125-138

Costa DP (1993) The relationship between reproductive and foraging energetics and the evolution of the Pinnipedia. In: Boyd IL (ed) Marine mammals: advances in behavioural and population biology. Symp Zool Soc Lond. Oxford University Press, Oxford, p 293-314

* Crawford K, Mcdonald RA, Bearhop S (2008) Applications of stable isotope techniques to the ecology of mammals. Mammal Rev 38:87-107

* Drago M, Crespo EA, Aguilar A, Cardona L, Garcia N, Dans SL, Goodall N (2009) Historic diet change of the South American sea lion in Patagonia as revealed by isotopic analysis. Mar Ecol Prog Ser 384:273-286

* Drago M, Cardona L, Aguilar A, Crespo EA, Ameghino S, Garcia N (2010) Diet of lactating South American sea lions, as inferred from stable isotopes, influences pup growth. Mar Mamm Sci 26:309-323

Eder EB, Lewis MN, Campagna C, Koch PL (2010) Evidence of demersal foraging from stable isotope analysis of juvenile elephant seals from Patagonia. Mar Mamm Sci 26: 430-442

Gales NJ, Mattlin RH (1997) Summer diving behaviour of lactating New Zealand sea lions, Phocarctos hookeri. Can J Zool 75:1695-1706

*Gales NJ, Mattlin RH (1998) Fast, safe, field-portable gas anesthesia for otariids. Mar Mamm Sci 14:355-361

Hall-Aspland SA, Rogers TL, Canfield RB (2005) Stable carbon and nitrogen isotope analysis reveals seasonal variation in the diet of leopard seals. Mar Ecol Prog Ser 305: 249-259

Hanson NN, Wurster CM, Bird MI, Reid K, Boyd IL (2009) Intrinsic and extrinsic forcing in life histories: patterns of growth and stable isotopes in male Antarctic fur seal teeth. Mar Ecol Prog Ser 388:263-272

* Hirons AC, Schell DM, St Aubin DJ (2001) Growth rates of vibrissae of harbor seals (Phoca vitulina) and Steller sea lions (Eumetobias jubatus). Can J Zool 79:1053-1061

* Ingram T, Costa Pereira R, Araújo MS (2018) The dimensionality of individual niche variation. Ecology 99: 536-549

Kernaléguen L, Cazelles B, Arnould JPY, Richard P, Guinet C, Cherel Y (2012) Long-term species, sexual and individual variations in foraging strategies of fur seals revealed by stable isotopes in whiskers. PLOS ONE 7 : e32916

Kernaléguen L, Cherel Y, Knox TC, Baylis AMM, Arnould JPY (2015a) Sexual niche segregation and genderspecific individual specialisation in a highly dimorphic marine mammal. PLOS ONE 10:e0133018

Kernaléguen L, Arnould JPY, Guinet C, Cherel Y (2015b) Determinants of individual foraging specialization in large marine vertebrates, the Antarctic and subantarctic fur seals. J Anim Ecol 84:1081-1091

Lowther AD, Goldsworthy SD (2011) Detecting foraging ecotypes in Australian sea lion (Neophoca cinerea) colonies using stable isotope analysis. Mar Mamm Sci 27: 567-586

* Matthiopoulos J, Smout S, Winship AJ, Thompson D, Boyd

Editorial responsibility: Clive McMahon,

Hobart, Tasmania, Australia
IL, Harwood J (2008) Getting beneath the surface of marine mammal-fisheries competition. Mammal Rev 38: $167-188$

McHuron EA, Walcott SM, Zeligs J, Skrovan S, Costa DP, Reichmuth C (2016) Whisker growth dynamics in two North Pacific pinnipeds: implications for determining foraging ecology from stable isotope analysis. Mar Ecol Prog Ser 554:213-224

Meyer S, Robertson BC, Chilvers BL, Krkosek M (2015) Population dynamics reveal conservation priorities of the threatened New Zealand sea lion Phocarctos hookeri. Mar Biol 162:1587-1596

*Meyer S, Robertson BC, Chilvers BL, Krkosek M (2017) Marine mammal population decline linked to obscured by-catch. Proc Natl Acad Sci USA 114:11781-11786

* Meynier L, Morel PCH, Chilvers BL, Mackenzie DDS, Duignan PJ (2014) Foraging diversity in lactating New Zealand sea lions: insights from qualitative and quantitative fatty acid analysis. Can J Fish Aquat Sci 71:984-991

Newsome SD, Clementz MT, Koch PL (2010) Using stable isotope biogeochemistry to study marine mammal ecology. Mar Mamm Sci 26:509-572

* Page B, McKenzie J, Sumner MD, Coyne M, Goldsworthy SD (2006) Spatial separation of foraging habitats among New Zealand fur seals. Mar Ecol Prog Ser 323:263-279

Ramos R, Gonzalez-Solis J (2012) Trace me if you can: the use of intrinsic biogeochemical markers in marine top predators. Front Ecol Environ 10:258-266

Rea LD, Christ AM, Hayden AB, Stegall VK and others (2015) Age-specific vibrissae growth rates: a tool for determining the timing of ecologically important events in Steller sea lions. Mar Mamm Sci 31:1213-1233

Robertson BC, Chilvers BL (2011) The population decline of New Zealand sea lions Phocarctos hookeri: a review of possible causes. Mammal Rev 41:253-275

* Sadou MC, Beltran RS, Reichmuth C (2014) A calibration procedure for measuring pinniped vibrissae using photogrammetry. Aquat Mamm 40:213-218

* Sargeant BL, Mann J, Berggren P, Krutzen M (2005) Specialization and development of beach hunting, a rare foraging behavior, by wild bottlenose dolphins (Tursiops sp.). Can J Zool 83:1400-1410

Silva L, Saporit F, Vales D, Tavares M, Gandini P, Crespo EA, Cardona L (2014) Differences in diet composition and foraging patterns between sexes of the Magellanic penguin (Spheniscus magellanicus) during the nonbreeding period as revealed by $\delta^{13} \mathrm{C}$ and $\delta^{15} \mathrm{~N}$ values in feathers and bone. Mar Biol 161:1195-1206

* Smolker R, Richards A, Connor R, Mann J, Berggen P (1997) Sponge carving by dolphins (Delphinidae, Tursiops sp.): a foraging specialization involving tool use? Ethology 103:454-465

Staniland IJ, Robinson SL (2008) Segregation between the sexes: Antarctic fur seals, Arctocephalus gazella, foraging at South Georgia. Anim Behav 75:1581-1590

Staniland IJ, Gales N, Warren LN, Robinson SL, Goldsworthy SD, Casper RM (2010) Geographical variation in the behaviour of a central place forager: Antarctic fur seals foraging in contrasting environments. Mar Biol 157: 2383-2396

Submitted: July 9, 2018; Accepted: November 13, 2018

Proofs received from author(s): January 22, 2019 